\title{
E1 universo identitario de Esteban de Garibay y Zamalloa
}

\author{
Esteban ANCHUSTEGUI IGARTUA \\ Universidad del País Vasco \\ (esteban.antxustegi@ehu.es)
}

\begin{abstract}
RESUMEN
En este artículo se analiza la época y el universo identitario de Esteban de Garibay y Zamalloa (15531600), cronista de Felipe II, que defiende la teoría del tubalismo para tratar de conectar el origen de los españoles con el personaje bíblico de Tubal.

Según esta teoría, Tubal se asentaría en España, y lo que caracteriza a diversos autores vascos del XVI es que defienden que la entrada y primer asentamiento de Tubal fue en las montañas cantábricas. En este sentido, los autores vascos del siglo XVI como Zaldibia, Poza o Garibay, no se limitan a sumarse al tubalismo, sino que tienen especial interés en identificar el mundo cantábrico con el primer asentamiento de Tubal.

El trabajo analiza esta posición identitaria, y se centra en Garibay, quien reiteradamente insiste en la "primigeneidad" de los vascos respecto a los otros pueblos de España, es decir, que son los españoles más originarios. $\mathrm{Y}$ en este sentido quiero reseñar la propia la condición de vasco de la que Garibay hace gala, que no es sino la forma más genuina $y$ significativa de la autoctonía española
\end{abstract}

PALABRAS CLAVE: tubalismo; identidad; linaje; Historia; vasco-iberismo; euskera; España

\begin{abstract}
This article is about the age and identity ideology of Esteban de Garibay y Zamalloa (1553-1600), Philip II's chronicler, that supports the theory of tubalism with the purpose of linking the Spaniards' origin with Tubal, the biblical character.

According to this theory, Tubal would had settled in Spain, and this idea gave rise to a theory suggested by the basque scholars of sixteenth century, who champion that the arrival and first Tubal's settlement took place in the cantabric mountains. The basque scholars of sixteenth century, like Zaldibia, Poza, or Garibay between others not only are agree with the tubalism theory, but they have a special concern in linking the Tubal's first settlement with the cantabric world.

This work analyzes this identitary proposal, focusing on Garibay's ideas and analysing his discourse on the basque people's condition pioneering of the other peoples from Spain. In this respect, it must be emphasized the basque condition of Garibay as the most genuine and meaningful form of the native spanishness
\end{abstract}

KEY WORDS: tubalism; identity; ancestry; History; Basque-Iberian; Basque language; Spain

Res tene, Verba sequentur

(Los hechos están, las palabras vienen después)

\section{Introducción}

En la actualidad la obra de Garibay está marcada por la condición de, casi desde su fallecimiento en 1599, de "estigmatizado" en la historiografía española, en tanto que reo culpable y condenado - que no confeso- de historiador falsario y fabulador — «falto de crítica»- al tomar por verdaderos ciertos cronicones.

Se le achaca, por tanto, falta de crítica y «credulidad» al incorporar ciertas fuentes a su explicación de los orígenes de España, tanto desde una concepción de la Historia en 
general como de la propia España original en particular, comportamiento éste que le llevó a dar como válido el tubalismo de Florián de Ocampo. Con esta decisión Garibay se hace partícipe de la formulación histórica de una tesis que tiene largo y harto paradójico recorrido historiográfico, y no tan historiográfico: la tesis vasco-iberista, propuesta a la que el propio Caro Baroja (autor que "ilumina" este trabajo sobre Garibay) ha dedicado varios textos.

Es cosa sabida que Garibay pecó de crédulo en más de una ocasión, principalmente en el primer tomo de Los XL Libros del compendio historial donde se trata de la Antigüedad de España, dejándose seducir por las fantasías tubálicas de Ocampo ${ }^{1}$ y ofuscarse, como dice don Julio, por documentos falsos cuyo contenido le parecía coherente, emparejándolos a otros tenidos por legítimos y originales².

Con todo, también es de justicia decir que Los XL Libros del compendio historial de las Crónicas y universal historia de los reinos de España, desde que se publicó en Amberes en 1571, fue una obra muy leída y aplaudida en su tiempo. Tan es así que el poderoso predicamento que adquirió contribuyó a formar escuela, que estableció una especie de canon histórico - con considerables aplicaciones políticas- en el más amplio sentido de la palabra, y marcó posteriores derivaciones en el campo de la lingüística... para devenir actualmente, una vez que recayó sobre él referido sambenito de la falta de crítica, en una obra casi maldita.

Y en este aspecto, siguiendo a Julio Caro Baroja ${ }^{3}$, me permito hacer una censura a la Historiografía española por su falta de comprensión y flexibilidad, al pretender explicar la mayor parte de las posiciones y pasiones del pasado a la luz de las luchas y tensiones del presente, "de su día y hora", como dice don Julio. "Y esto es grave -continúa Caro Baroja-, porque del pasado surge el presente, pero claro es que el pasado no puede tener los caracteres del presente. Y hoy, ante la conciencia colectiva, hipersensible para los asuntos del día y desdeñosa para todo lo anterior, que se ha formado de modo tan deliberado como torpe, acaso sea más necesario que nunca el afinar en la empresa de estudiar los nexos de nuestra vida social y de nuestras ideas, con la vida de los hombre de

${ }^{1} \mathrm{~J}$. CARO BAROJA, Los vascos y la Historia a través de Garibay, Editorial Caro Raggio, Madrid, 2002, 176 y ss.

${ }^{2} \mathrm{~J}$. CARO BAROJA retoma esta cuestión con mayor amplitud en Las falsificaciones de la Historia (en relación con la de España), Editorial Seix Barral, S.A. Colección Biblioteca Breve, Barcelona, 1992; donde dedica un capítulo a "Garibay y el tubalismo vasco".

${ }^{3}$ J. CARO BAROJA, Los vascos y la Historia, 28-30. 
otras épocas, y con .lo que pensaron”.

\section{La sociedad banderiza}

La propia historia de Esteban de Garibay y Zamalloa, nacido el 9 de marzo de 1533 en Mondragón (Guipúzcoa) no podía sustraerse de la refriega banderiza que desde el siglo XIII al XV asoló el País Vasco, produciendo acontecimientos como la quema de Mondragón, durante la noche de San Juan del año 1448, así como los sucesos que se desarrollaron a raíz de este acontecimiento.

El bando, como una consecuencia de la organización social en linajes, no era privativo de la sociedad vasca, y ha tenido su época de esplendor en sociedades campesinas de zonas montañosas, desde Escocia hasta las tierras pobladas por bereberes. En ellas, la constitución del linaje da a los hombres que pertenecen a él una serie de derechos y deberes con respecto a otros parientes por consanguinidad que descienden del tronco común de varón en varón, otorgándoles privilegios y obligaciones que suelen fijarse por medio de leyes no escritas, pero conservadas por la tradición oral y transmitidas de padres a hijos.

También hay cierta épica y poética en la transmisión de estas normas y principios, donde la consideración de la deuda de sangre, la obligación de la venganza o el procurar el dominio efectivo de un linaje sobre otros constituyen puntos esenciales de esta organización. Los linajes viven en lucha, haciendo y deshaciendo alianzas, a causa de de tierras y preeminencias que se disputan: control sobre mercados rurales, control sobre gentes que ocupan posiciones subordinadas, dominio de patronatos de iglesias y cobro de sus diezmos, etc.

Los bandos vascos realizaron sus violencias "de Ebro a la mar", como dice Garibay, llegara o no acá "el fuego de Castilla" ${ }^{4}$. Para Julio Caro Baroja "es probable que la división quedara condicionada por la enemistad de dos grandes linajes en su origen. Uno el de los Mendoza que, en una época en que el condado de Álava andaba revuelto, parecen haberse inclinado hacia Castilla, y el otro el de los Guevara, que se inclinaban más hacia Navarra"5. Este enfrentamiento se trasladó en años posteriores a Guipúzcoa y

\footnotetext{
${ }^{4}$ E. de GARIBAY Y ZAMALLOA, "Memorias de Garibay", en Memorial histórico español, Real Academia de la Historia, v.VII, Madrid, 1854, 20-21 (libro I, título VI).

5 J. CARO BAROJA, "Linajes y bandos", en Vasconiana, Estudios Vascos III, Editorial Txertoa, San Sebastián, 1986, 36.
} 
Vizcaya. Esta organización de linajes con un «pariente mayor» o cabeza conocido, en unos ámbitos rurales en esencia, hizo que se fueran sumando motivos de lucha diferentes en el tiempo y en el espacio. Así, el bando «oñacino», cuyo nombre deriva del linaje guipuzcoano de Oñaz, tuvo por cabeza de bando en sus principios al linaje alavés de los Mendoza; mientras que el bando «gamboíno» deriva su nombre del linaje de Gamboa, que tiene su origen en el de Guevara. En Vizcaya tuvieron gran protagonismo los oñacinos Butrón y los gamboínos Avendaño, hasta el punto de que hubo de intervenir personalmente el señor de Vizcaya para poner paz en las sangrientas reyertas. También en Navarra los unidos en torno al linaje de los Agramont, los agramonteses, se solidarizaron con los gamboínos, mientras que los partidarios del linaje de Beaumont, los beamonteses, lo hicieron con los oñacinos ${ }^{6}$.

Lope García de Salazar, uno de aquellos banderizos, escribió en el siglo XV (entre 1471 y 1474) un conjunto de libros a los que tituló Las Bienandanzas e Fortunas en los que relata numerosos episodios relacionados con las banderías, y donde da cuenta de los orígenes y el hilo del relato de las luchas de linajes y bandos que marcaron la historia del país en los siglos XIII y XV. Este magno trabajo nos adentra en el trasmundo ideológico que enmarca la razón autobiográfica de su obra con una descripción al detalle, fijando el sentido de dos conceptos clave en la historia cultural del pueblo vasco con una precisión que sólo quien los tiene y siente puede dar: la «solidaridad agnática» y el «más valer», conceptos activos a la sazón en torno a esa idea fundamental del «linaje» que enardece las eresi femeninas $-\mathrm{O}$ iletac ${ }^{7}$ como prefiere Azkue ${ }^{8}$ - tan apreciadas por Garibay ${ }^{9}$-la mujer, dice Caro Baroja, "sentía los conflictos de linaje tanto como el varón"10_, y que están asociadas a la de «territorio», donde la figura protagónica de la mujer tiene largo y ancho recorrido después.

Asimismo, hipótesis e interpretaciones más recientes señalan otras causas que complementan las anteriores. Por un lado la oposición entre una alta y antigua nobleza

\footnotetext{
${ }^{6}$ J. CARO BAROJA, ibidem, 39.

7 Endechas o cantos fúnebres.

8 R. Ma AZKUE, Euskalerriaren yakintza, Lenengo liburua: oitura ta sineskeriak, Espasa-Calpe, Madrid, 1959, 233; y Diccionario Vasco-Español-Francés, Edit. La Gran Enciclopedia Vasca, Bilbao, 1969, 255-256 y 409.

9 L. MICHELENA, Textos arcaicos vascos, Diputación Foral de Guipúzcoa, San Sebastián, 1990, 75-79 y 9092.

10 J. CARO BAROJA, op. cit., 434.
} 
rural, que basaba su riqueza en el ganado, los oñacinos ${ }^{11}$. Los gamboínos, por el contario, se nutrían en la pequeña nobleza rural, apoyada económicamente en la agricultura, el comercio y las villas. Incluso amabas realidades se reflejaban en la composición de las huestes de ambos. Así, los oñacinos estaban sustentados en los caballeros montados, mientras los gamboínos contaban con mayor número de ballesteros. Finalmente, la lucha entre unos y otros enmascaraban la oposición de intereses entre villas y mundo rural.

El caso es que durante mucho tiempo, los clanes vascos estuvieron divididos en dos grandes bandos, el oñacino y el gamboíno, cuyas continuas guerras dividieron el País y sembraron el pánico entre los campesinos. Todo ello ocasionó terribles guerras civiles, obligando a que los pobladores estuvieran divididos en bandos que representaban las dos parcialidades mayores.

En este contexto, también Mondragón se vio amenazado por las pretensiones del señor de Oñate, que reclamó contra ciertos nombramientos reales que consideraba como desafueros. La familia Guevara ostentó el Señorío de Oñate desde 1149 hasta su anexión a Guipúzcoa en 1845. Hasta 1201 los señores de Oñate eran vasallos del rey de Navarra y luego pasaron a serlo del rey castellano, dependiendo directamente del rey. Los Guevara, destacados miembros del bando gamboíno, durante los siglos XIII y XIV adquirieron el patronato del monasterio de San Miguel y el control de las ferrerías de Zubillaga.

La realidad banderiza también había producido en Mondragón una hostilidad entre los partidarios de Guraya, representante del bando oñacino, y los de Báñez de Artazubiaga, de la facción gamboína, lo que desembocó en el famosísimo incendio que relata Garibay en sus "Memorias"12, provocado por las tropas del señor de Oñate al mando de Pedro Vélez de Guevara en 1448. Esta quema y posterior saqueo de Mondragón fue una de las más brutales consecuencias de la lucha y acaso uno de los hechos que más contribuyeron a desacreditar la forma de actuar de los banderizos.

El propio Garibay, mondragonés pero cuyo linaje de «parientes mayores» era originario de Oñate ${ }^{13}$, no podía olvidar estos acontecimientos, aunque era consciente de que había que defenderse de los apetitos de hombres poderosos que aspiraban a dominar sobre villas de origen real, ricas y populosas, para gozar de sus tributos, haciendo que los

\footnotetext{
11 A. de OTAZU Y LLANA, El 'igualitarismo' vasco: mito y realidad, Editorial Txertoa, San Sebastián, 1973, 22.

${ }^{12}$ E. de GARIBAY Y ZAMALLOA, op. cit., 148-156 (libro II, título IV).

${ }^{13} \mathrm{~J}$. CARO BAROJA, Los vascos y la Historia, 74-75, en nota.
} 
reyes, débiles y necesitados, se los cediesen. En este sentido, nuestro autor estaba más de parte de una organización basada en el mutuo respeto de la monarquía, la provincia y las villas, que en la prepotencia de los linajes o de los empleados reales. Así, cuando en el Compendio Historial, de modo mucho más sucinto que en las "Memorias", cuenta la quema de Mondragón, expone cómo fue castigado Pedro Vélez de Guevara a dos años de prisión y a sufrir fuertes multas pecuniarias, y siendo obligado, además, a resarcir a los mondragoneses por los daños y perjuicios que habían experimentado con la quema de sus casas. Asimismo, Garibay contará también con satisfacción cómo las hermandades de Guipúzcoa derribaron las torres que los Guevara tenían en Mondragón “donde muchos vandoleros malhechores se recogían”, y otra que poseían en Salinas ${ }^{14}$. Pero más se explaya aún al tratar de la famosa y sistemática demolición de las casas-torre (vivienda de los «parientes mayores», jefes de un linaje o bando, que defendían su pequeño territorio del bando opuesto), hecha por Enrique IV de Castilla tanto en Guipúzcoa como en Vizcaya ${ }^{15}$. En este sentido, es curios -como resalta J. Caro Baroja- el papel de un rey tan desdichado en una medida importante, aunque no decisiva, para poner orden interno en el país ${ }^{16}$. Con todo, el mal duró hasta el tiempo de los Reyes Católicos.

\section{Guipúzcoa y su hierro}

Así, las historias de lo banderizos aluden a destrucciones, efectuadas en ferrerías, que pueden explicar un aspecto esencial de la vida de Mondragón en los tiempos de los abuelos de Graibay.

Y si hablamos de ferrerías, en los Libros del compendio bistorial el hierro está en todas partes ${ }^{17}$. En su descripción general nos trazará un cuadro minucioso de la producción siderúrgica de Guipúzcoa: “Abunda esta tierra de muchas de muchas herrena de hierro, cosa , tan necesaria a la vida humana, d'el qual no solo se lleva a Castilla, pero a Francia, Ynglaterra, Flandes, Ytalia, Sicilia, y otras provincias de la Europa, y también a África, y aun a las Indias Orientales de Asia, y otras provincias, donde los portugueses tienen su

\footnotetext{
${ }^{14}$ E. de GARIBAY Y ZAMALLOA, Los XL libros d'el compendio historial de las chronicas y vniuersal historia de todos los reynos de España, Christophoro Plantino, Amberes, 1571, II, 1144 (libro XVI). El original procede de la Universidad Complutense de Madrid, y está digitalizado el 18 de agosto de 2009. Se puede acceder en: http:// books.google.com/ books/ about/ Los_XL_libros_d_el_compendio bistorial_d.html?id= bRSIThGXl6kC

15 E. de GARIBAY Y ZAMALLOA, ibidem, cap. VIII, S 1.

${ }^{16} \mathrm{~J}$. CARO BAROJA, Los vascos y la Historia, 70.

${ }^{17}$ E. de GARIBAY Y ZAMALLOA, Compendio Historial, II, 970-971 (libro XV).
} 
comercio y navegación, y también al nuevo mundo, llamado comúnmente Indias Occidentales". Y también barre para casa: “También se labra hazero, pero en sola la villa de Mondragón, siendo el mas fuerte, que se sabe hazer en parte alguna, en tanto grado, que aunque de una espada, o otra cualquier arma, labrada d'este metal, se torne a hazer cinco o seys cosas, en cada una tornando al fuego, nunca pierde su valor y fortaleza, lo que el hazero de Milan y otros haceros no hanian".

No cabe duda de que Garibay vivió presionado por la tradición ferrona mondragonesa, que producía aceros y también leyendas: leyendas vinculadas a aquella peña de forma bella y majestuosa que domina todo el ámbito del municipio. El microcosmos de la niñez y juventud le hace pensar en cosas remotas, grandiosas del macrocosmos. Y he aquí la ferrería mondragonesa de «Babilonia». Encima está la peña, que bien pudo pensar en la torre de Babel: "Esta notable y grande peña, que del nombre de una pequeña población, llamada Udala, donde ay una habitación de unos pocos caseros, que están en medio d'ella, se llama Udalacha, que quiere decir peña de Udala, es una de las cosas más altas que ay en todos los reynos d'España, y hermosa y fructífera, especialmente de metales, y tiene conjuncta otra muy alta peña, llamada Amboto, que las dos parecen hermanas, que nacieron para hermosear la una a la otra, y cerca del monte Gordeya están ambas, pero esta les excede en su fertilidad y grande abundancia de metales de hierro y hazero, el qual se labra del metal d'esta peña, siendo el mas rezio de la Europa..."18

Garibay asocia su paisaje natal con aquel más que problemático patriarca Tubal, sobre cuya venida se sentará la base de la historia de la España primitiva, y partiendo de la magnificación de una montaña familiar, su hierro y la existencia de una ferrería -que para confusión de propios y extraños se llamaba Babilonia- ya tiene nuestro autor los primeros elementos inmediatos para confirmar una teoría.

\section{Del régimen de linajes a la burguesía burocrática}

Con el fin de la guerra de banderías, a partir de la segunda parte del siglo XV, en Guipúzcoa empieza a crearse una especie de burguesía burocrática, que aumenta en tiempos de los Reyes Católicos y que alcanza un considerable desarrollo en la época de los padres de Garibay y de él mismo, y no siendo Mondragón la villa que dé menos ejemplos

\footnotetext{
${ }^{18}$ E. de GARIBAY Y ZAMALLOA, ibidem, I, 86 (libro IV, capítulo II).
} 
a este respecto.

No procede ahora hacer un repaso de maestros renacentistas vascos como el famoso calígrafo durangués Juan de Iciar (autor del famoso Arte de escribir, una Aritmética o el libro con modelos de estilo epistolar Nuevo estilo d'escrevir cartas mensageras; su discípulo el arratiano Pedro de Madariaga, autor de Honra de escribanos, que incluye un capítulo de nombre bien significativo: "De los inventores de las letras, y ortographía en lengua Vizcayna, y quán elegante y antiguo es este lenguaje"; o Felipe de Zabala, autor la Introducción nueva del arte de escribir, oriundo de Marín, en el valle de Léniz (que incluye también la población de Mondragón) y hermano de Tomás, que también trabajó en la corte, por citar sólo algunas de las personalidades que a lo largo del siglo XVI dieron una marcada superioridad a los vascos en las oficinas reales, en los Consejos, y al lado del Rey y de sus primeros ministros. Esta preeminencia en los cargos de secretario, hombres de confianza y otras funciones administrativas ejercidas por los vascos irá en aumento, lo que, unido a otras aptitudes de en el manejo de negocios públicos y privados, llegará a ser considerada abusiva para algunos allá en la época de Felipe IV.

Del siglo XV al XVI en el rincón familiar de Garibay se da un tránsito social significativo que franquea de un régimen de linajes y bandos a una burguesía burocrática. En este sentido, nuestro historiador ya pertenece a esta última, aunque su raigambre familiar se halla inmersa de modo aún cercano en el régimen de linajes. Y estos dos hechos condicionaron toda su actuación como historiador y genealogista.

Julio Caro Baroja explica esta paradoja y este encuentro entre dos mundos de una forma extremadamente bella: "En nuestro País Vasco, considerado en la Edad Media y después tierra selvática y arcaizante en esencia, han ocurrido dos hechos de significado extraño y profundos en un lapso de tiempo relativamente corto. Ya cayendo el siglo XV, un anciano cercado por sus propios hijos en cierta sombría torre de linaje vizcaína, distrae sus penas, componiendo nada menos que una Historia Universal. Este anciano fue Lope García de Salazar. Menos de un siglo después, en el arrabal de una villa guipuzcoana, un joven llega a enfermar empeñado en la en la tarea de escribir una Historia de España, desde los tiempos más remotos hasta el propio. Éste fue Esteban de Garibay. Algo tienen de común en sus inquietudes y concepciones. Bastante, también, de diferente. No en balde han pasado años decisivos en la Historia de Europa y de modo concreto en la España y sus vidas no tienen de paralelo más que el quehacer intelectual. Lope García es 
aún un banderizo y concibe la Historia como tal. Garibay ya no lo es, aunque está cerca de quienes lo fueron. Los dos, sin embargo, piensan que el linaje da, o quita, a los hombres todo. Los dos creen que la vida es, en esencia, lucha. Más claro y explícito será el primero que el segundo; pero al segundo le moverán inquietudes superiores y de orden más general"19.

\section{Concepciones de la Historia}

Ya indiqué en la Introducción cómo la obra de Garibay ha sido maltratada, en exceso, desde el siglo XVII, porque, alguien con muy mala intención le achacó pronto de plagiario y después se sucedieron otras acusaciones. Tampoco el esfuerzo que realizó para ordenar la historia de Navarra se lo agradecieron algunos historiadores del país, acusándole de guipuzcoanismo. En definitiva, Garibay, como historiador de los viejos reinos peninsulares o como lingüista especulativo ha sido vilipendiado y colocado bajo sospecha.

Pero esta posición no fue siempre así, y tiene un punto de inflexión en lo que Julio Caro Baroja llama rigorismo y está representado por el padre Flórez:

"Los resultados de tal rigorismo histórico son bastante comparables a los del rigorismo moral, porque el historiador rigorista, sea el agustino, sea antes el cronista de Aragón, argumenta muy bien, en conjunto, para deshacer quimeras. Llega a tener una fe ciega en ciertos documentos, porque ha aplicado en ellos sus criterios propios y le han respondido a satisfacción. Esto no quiere decir que respondan igual en otras cabezas. A veces el rigorista, para construir de modo coherente, desprecia noticias que no son despreciables. Y no faltan casos en que el rigorista no es tan riguroso como parece o se proclama".

(...) Ahora bien, aceptadas todas las exigencias de la crítica textual, moderna, adoptadas todas las reglas de la Heurística, siempre nos queda algo que hacer con los historiadores y los textos que presentan deficiencias en este orden, porque hay cuestiones que rebasan éstas (sobre las que se pone tanto énfasis) que son fundamentales para el historiador y acerca de las cuales los hipercríticos no dicen gran cosa de provecho..., mientras que de un texto ambiguo como los de Garibay mismo, ocupado de cosas muy remotas, se extraen ideas o cuando menos sirven para plantear problemas. En efecto, Zurita escurre el bulto, pensando que lo mismo dan los testimonios de Polibio que cualquier fábula griega, $y$, no trata, así, de la Antigüedad. Garibay se deja ofuscar (y no es el único según va dicho) por documentos falsos, pero los combina con otros

${ }^{19} \mathrm{~J}$. CARO BAROJA, Los vascos y la Historia..., 77-78. 
verídicos. De esta combinación sale algo que, en sí, es interesante para el historiador en épocas posteriores, que puede separar, con mayor comodidad que los del Renacimiento, al grano de la paja. Garibay cree también poder dar a la Historia Antigua de la península ibérica una coherencia; que esto sea posible o no es tema que aún se debate. Hay historiadores actuales que, como tema notorio, piensan que no puede hablarse de tal coherencia hasta muy tarde. Otros (y estos son hasta cierto punto herederos de nuestro mondragonés) creen que hay bastantes claves que permiten hablar de una «Historia de España» que empieza con los sucesos de la más remota Antigüedad.

No será la razón que justifica la idea de coherencia en el siglo XVI igual que la razón desarrollada en el siglo XX, pero acaso los ideales cardinales de unidad que han gravitado sobre la conciencia de los historiadores modernos, que no han tenido miedo a hablar de una «España Antigua», eran parecidos, en mucho, a los que tenía Garibay. En otro orden, claro es, las derivaciones de la idea unitaria de éste y las ideas políticas que se pueden extraer de las de nuestros eruditos contemporáneos son distintas. Pero si en el siglo XX resulta que un historiador piensa en el «vasco-iberismo», como hipótesis que justifica cierta unidad primitiva, claro es que, siguiendo la historia de esta hipótesis hasta que se formula, llegaremos a topar con Garibay. Escusado será decir también que la tesis vasco-ibérica no la defendía aquél con el aparato crítico o la erudición de un Hugo Schuchardt o de un Menéndez Pidal... pero éstos tienen su antecedente en Guillermo de Humboldt, Humboldt en Hervás y Hervás en Astarloa y Astarloa en Baltasar de Echave, Poza, en fin, don Esteban de Garibay y Zamalloa. Ni más ni menos"20

\section{Vasco-iberismo y euskera}

Por la defensa de la tesis vasco-ibérica o vasco-iberista ya habían mostrado extremado interés, entre otros, Lucio Marineo Sículo en sus Cosas Memorables de España (1539) y, con opinión significativa -y sugerente- Ambrosio de Morales en su prosecución de La crónica general de España que adelanta en 1573, dos antes del fallecimiento de Juan Martinez de Zaldibia, diputado y tres veces alcalde de su villa natal, que hacia 1560 había escrito Suma de las cosas cantábricas y guipuzcoanas, obra de primer interés historiográfico que presenta los fundamentos del vasco-iberismo, reseñando dos ideas básicas en torno a la historia del euskera: fue la primera lengua y universal en la Península, traída por Tubal y sus descendientes tras la dispersión de Babel, y es una lengua que se ha mantenido pura y sin

\footnotetext{
20 Los vascos y la Historia..., 177-178. Para aclarar esta cuestión también es interesante el artículo de J. CARO BAROJA "Observaciones sobre la hipótesis del vasco-iberismo, considerado desde el punto de vista histórico”, en Emérita, X, 2, 1942, 236-238.
} 
cambios a través de los siglos. Esta obra, como la ya mencionada de Lope García de Salazar, conoce impresión tardía, y ambas hacen apología de lo vasco, recogiendo como pruebas fragmentos de cantares antiguos vascos como los de Beotibar y Juan de Lazcano ${ }^{21}$. A lo que habrá que añadir la obra de nuestro autor, Esteban de Garibay, publicada en 1571 con el nombre de Los XL Libros del Compendio historial de las chronicas y universal Historia de todos los reynos de España.

También contemporáneo de Garibay es el licenciado Andrés de Poza, quien da a las primeras prensas vizcaínas de su amigo Mathias Mares, primero su tratado de náutica Hydrographia, y luego la mejor conocida De la antigua lengua, poblaciones y comarcas de las Españas, en que de paso se tocan algunas cosas de la Cantabria, fechada en 1587. En ella, el erudito letrado orduñés da origen asirio-babilónico al tocado corniforme vasco tradicional, insiste en la misma línea al ocuparse de la «babilónica lengua vascongada», e incluye un diccionario toponímico con etimologías vascas para demostrar su identificación de cántabros y vascos, tan firme que él mismo se identifica como Andreae Pozas Iuribcoub Cantabri22.

Me voy a detener algo en Pozas y en su propuesta, quien, para Juaristi23, es el seguidor más claro del cratilismo entre los apologistas vascos. Esta posición, acorde con la tendencia dominante en el pensamiento neoplatónico del Renacimiento, supone la atribución a los hablantes de las lenguas matrices de un conocimiento directo, recibido de Dios e infuso en sus almas con la lengua misma, de las ideas eternas, preexistentes en la mente divina al acto de la creación del mundo. Así, para Juaristi, para demostrar la primacía del euskera, Poza utilizó las mismas armas de los judíos conversos, que eran sus adversarios, y los de sus compatriotas a la hora de ocupar los puestos en la administración. Esas armas eran el método cabalístico que, como hemos indicado antes, al igual que el cratilismo, cree en una relación directa entre la lengua y el mundo.

En el capítulo XII de su libro Poza quiere probar la excelencia de la lengua vasca, y para ello propugna que es una lengua «natural». El siguiente pasaje es bastante extenso,

\footnotetext{
21 J. MARTINEZ DE ZALDIBIA, Suma de las cosas cantábricas y guipuzcoanas del bachiller Juan Martinez de Zalidibia, Edición, Introducción y notas de F. Arocena, Diputación de Guipúzcoa, San Sebastián, 1945, 3863.

22 A. de POZA, De la antigua lengua, poblaciones, y comarcas de las Españas, en que de paso se tocan algunas cosas de la Cantabria. Compuesto por el Licenciado Andrés de Poza, natural de la ciudad de Orduña, y abogado en el muy noble y leal Señóo de Vizcaya, Mathias Mares, Bilbao, 1587, ff. 1-36, 59.

${ }^{23}$ J. JUARISTI, Vestigios de Babel. Para una arqueología de los nacionalismos españoles, Siglo XXI Editores, 1992.
} 
pero merece la pena, porque recoge muy bien la idea del cratilismo:

"CAPITVLO XII En que se muestra cómo la lengua Vascongada no es menos substancial y philosóphica que las más elegantes de Europa.

Tiene se por lengua excelente la que en los mismos nombres enseña assí la causa dellos como la naturaleza y difinición de la cosa que se nombra, de la qual consideración resultó la disputa de Platón en Cratilo, sobre si los nombres eran impuestos a caso, o divinamente, porque en las lenguas que se pueden dezir elegantes, sustanciales, y philosóphicas, hallaremos no sólo la demonstración, mas también el sentido y difinición de la cosa. Pero en las que no son tales, sino mestizas y imperfectas, no hallaremos más de solos los nombres, sin tener mas misterio de que la tal cosa fue llamada assí; en el qual caso podremos dezir que la tal lengua fue y es casual del todo.

Pues como las hazañas de Dios sean siempre fundadas en una sabiduría altíssima, assí también es de creer que las setenta y dos lenguas Babilónicas, como emanadas de Dios, sin duda fueran de muy profunda elegancia, y ésta de manera que, según buena razon, no uviera vocablo ocioso, ni sílaba que careciesse de misterio. Porque una diferencia tan artificiosa que en ningún vocablo se encontrasse la una con la otra, assí como tampoco los rostros, ni aun los animales tengan semejança total, quién duda sino que tan memorable hazaña en todo y por todo tuviera su misterio, qual de la sabiduría divina no pudiera ser menos que en perfectión muy acavada. De suerte que avemos de entender dos cosas: la primera, que en cada una de las lenguas Babilónicas, el mismo nombre nos muestra alguna causa o occulta propriedad de la cosaporque fuesse llamada assí, y la segunda, que el nombre que no tiene esto esadvenedizo, adulterino, casual, y no natural a la tal lengua" 24

El libro de Poza defiende la antigüedad del euskera en la Península contra los partidarios del caldeo, en su mayoría judíos, quienes pensaban que la patria de Tubal estaba en Caldea. Esta tesis decaerá tras el Concilio de Trento, conforme se intensifica el antijudaísmo. Para defender sus ideas Poza recurre a los autores clásicos (Séneca, Pomponio Mela, Estrabón...) y a explicar la toponimia antigua de la Península mediante el euskera. Se esfuerza en mostrar las grandes diferencias existentes entre el euskera y el latín. Está convencido, como tantos otros de la época, de que ningún invasor ha conseguido entrar en tierra de vascos y que, por tanto, en el País Vasco se mantienen los primeros habitantes de la Península.

Para defenderse de los que piensan que en la Península se hablaba más de una

\footnotetext{
${ }^{24}$ A. de POZA, De la antigua lengua...., 30r-31r.
} 
lengua (Morales, Mariana, Florián de Ocampo...) argumenta que las distintas lenguas que entraron en la Península fueron através de invasiones, pero para entonces ya estaba allí el euskera, como única lengua. Sin embargo, es de los que piensan que, siendo el hebreo la primera lengua, debió sin duda estar antes incluso que el euskera en la Península. Para probar esto, utiliza algunos topónimos y los nombres de los reyes míticos (la falsa lista del dudoso Annio de Viterbo, que luego analizaremos con Garibay), de los cuales los primeros ocho vendrían del hebreo, y los siguientes del vasco (cap. III). Con todo, el hecho de que el hebreo precediera al euskera no quiere decir que fuera la primera lengua de España, ya que las naciones surgieron de la confusión de Babel.

Además, para reforzar esta idea y abundando en el cratilismo, Poza equipara lengua natural con lengua matriz, mientras que las lenguas arbitrarias serían las lenguas derivadas, las lenguas contaminadas. Para ello nos ofrece varios ejemplos. Su método está basado en la etimología tradicional fundamentalmente de corte cratílico: separar la palabra en raíces, deducir de las raíces el significado original de la palabra, y comparar ese significado oculto con el de otras lenguas. Por ejemplo:

"Eriotcea, significa en Vascuence la muerte, y significa golpe, herida, o accidente frío, en que se encierra una breve substancia philosóphica. Porque como la frialdad sea enemiga de la generación y de la vida, y la vejez fenezca en esta frialdad, assí para que sepamos lo que es muerte, se nos deletrea por el oppuesto de la calor templada, o lo caliente y húmedo predominante en que la vida se conserva. Mors en Latín, Thanatos en Griego, doot en la lengua Septentrional, sólo nos significan la muerte a secas, sin otra doctrina alguna, excepto que el Septentrional no dexa de apuntar que la muerte es una resolución, o derretimiento de humores" 25

Por lo tanto, las palabras de las lenguas matrices tienen un significado adicional, que muestra una sabiduría que les es propia, que muestra la esencia, la naturaleza de las cosas. Pero la sabiduría mayor a que puede aspirar el ser humano es a conocer la naturaleza divina:

"A Dios omnipotente, llama el Vascongado jeaun, en una sílaba sincopadamente pronunciando todas las vocales, como si no hizieran más de una sílaba, el qual vocablo significa en Vascuence tú mismo bueno, sentencia por cierto la mas alta y breve que a Dios trino y uno, para denotarle que lo es, podría atribuyrle. A esta elegancia confirma que como sin las cinco vocales ninguna pronunciación se puede

25 A. de POZA, ibidem, 34v. 
pronunciar ni concepto manifestarse, assí en este nombre Ieauna, que es compuesto de las cinco vocales, se apunta que ni forma ni materia consiste sin aquel Dios que dio ser a todas las cosas"26

Deriva ieaun (en realidad iaun o jaun «señor») de un supuesto ieaoun, que contiene las cinco vocales. La etimología es i-a-on («tú-mismo-bueno»), que equivaldría a la Trinidad, el Padre, el Hijo y el Espíritu Santo. De esta manera, Poza quiere explicar el nombre de Dios mediante las vocales, en contra de lo que se esperaría del método cabalístico $-\mathrm{y}$, en último término, en contra de los judíos- pues, al tratarse el hebreo de una lengua semítica, toda etimología habría de basarse fundamentalmente en las consonantes. De esta manera quiso probar que Dios aclaró su nombre (el misterio de la Trinidad) a los descendientes de Tubal, a los vascos. Y, de paso, el euskera aparecía como lengua más perfecta que el hebreo, dado que era una lengua filosófica y teológica. El corolario es que los vascos fueron cristianos incluso antes de Cristo, tratándose éste de otro de los mitos viz̧aínos: el del monoteísmo primitivo (Aranzadi ${ }^{27}$ ).

\section{E1 destino de Garibay y de sus 'papeles'}

El punto de arranque de Garibay en su Compendio historial es la consideración de unos textos falsos, como lo son los publicados a fines del siglo XV por G. Nanni, o Annio de Viterbo, acerca de los primeros reyes de Hispania ${ }^{28}$. Arranca la lista nada menos que del patriarca Tubal y contiene hasta veintisiete monarcas de toda la península. La obsequiosidad del falsario con respecto a los Reyes Católicos parece evidente. Pero los fragmentos del falso Beroso, una de las «lagunas inmundas» que habían producido vapores nefastos para los historiadores españoles antiguos (la otra la había constituido «la vanidad antigua de los griegos impostores») ${ }^{29}$ dieron lugar a un afianzamiento de lo que

\footnotetext{
26 A. de POZA, ibidem, 33r.

${ }^{27} \mathrm{~J}$. ARANZADI, Milenarismo vasco (Edad de oro, etnia y nativismo), Taurus Ediciones, Madrid, 1981.

${ }^{28}$ Los fragmentos de Beroso, sacerdote caldeo, y de otros autores fabulosos, produjeron grandes luchas entre los eruditos del Renacimiento. Julio Caro Baroja nos conduce hasta Pierre BAYLE, Dictionnaire bistorique et critique, XI (París, 1820), 1-4, quien da elementos suficientes para obtener idea de ello, con referencia a varios eruditos españoles que tuvieron opiniones encontradas sobre la autenticidad (CARO BAROJA, Los vascos y la Historia..., 193). Annio de Viterbo, G. Nanni (1452-1502) publicó sus textos en 1497. Para unos Annio fue un falsario, mientras que para otros fue engañado. Sea como fuese, la obra se imprimió muchas veces, y de él depende de modo abundante y profuso Florián de Ocampo, y de quien Garibay es adepto.

${ }_{29} \mathrm{~J}$. F. de MASDEU, Historia crítica de España y de la cultura española. Citando a Caro Baroja (Los vascos y la Historia..., 193), Masdeu se ocupó, en las 38-53, al tratar de la «España fabulosa», de Annio y de sus escritos para defender la tesis de que los más fuertes impugnadores que tuvo fueron españoles o hispanos
} 
podría llamarse «Tubalismo étnico», con la base política de un monarquismo primitivo, cuya autoridad se extendería con «Ibero» (el segundo de la serie real fingida) y otros epónimos clásicos.

Es cierto que Garibay se dejó llevar por Annio o de quien en realidad falsificara los textos, aunque es más cierto que lo que le hizo aceptar la lista fue el haber leído y releído la obra de Florián de Ocampo, personaje que siempre ha causado la curiosidad de los hispanistas y que es mucho más equívoco y fantástico que Garibay. Ocampo sigue principios muy particulares al escribir la Historia Antigua de España, y muchos de sus relatos parecen inspirados en los libros de caballerías. Así, los que tuvieron en cuenta y continuaron sus proyectos debieron pasar no pocas zozobras, empezando por su amigo Ambrosio de Morales, continuador de su obra, y citado con anterioridad.

Y también es evidente la dependencia de lo que escribe Garaibay de Los cinco primeros libros de la crónica general de España ${ }^{30}$ debidos a Ocampo, quien ha sido, en gran parte, el causante del descrédito del historiador guipuzcoano, porque en el libro primero de su Crónica introdujo el contenido del falso Beroso y cuanto halló en Annio de Viterbo, «corregido»y «aumentado». Tenía Ocampo gran preocupación por la Toponimia y la relacionó con la Antroponimia. Así, de acuerdo con las reglas que extrajo de los textos falsos, y mezclando doctrina que obtuvo de otros auténticos, escribió una gran cantidad de folios (trescientas treinta y seis, impresos por los dos lados) en un tono machacón y reiterativo que llegan hasta la muerte de Cornelio Escipión ${ }^{31}$.

Con todo, las diferencias -sustanciales- entre Ocampo y Garibay se hallan en la interpretación de los textos, tanto desde un punto de vista lingüístico como geográfico. Ocampo, por ejemplo, cree que la primera región donde «dicen» paró Tubal fue Andalucía y no habla de tierra vasca. Y si Setubal, según Ocampo, tiene que ver Tubal, también pueden estarlo Tafalla (por «Tubaila») y Tudela (por «Tubella») según Garibay. La consecuencia de todo ello fue que los tubalistas se derramaron por España, buscando

en el sentido más lato de la palabra. Recuerda, así, a Gaspar Barreyros, a Luis Vives, del que traduce un texto de 1524, Andrés de Resende, Melchor Cano, Antonio Agustín y más tarde Mariana, Lupercio Leonardo de Argensola, Bartolomé Llorente, sin contar a Juan de Vergara, Benito Pereyra y Juna de Pineda. Era, pues, injusticia la de ciertos eruditos italianos que pretendían cargar a los españoles la tacha de haber aceptado casi unánimemente la autenticidad.

${ }^{30} \mathrm{~F}$. OCAMPO, Los çinco primeros libros de la Cronica general de España, que recopila el maestro Florian do Campo, Cronista del Rey nuestro señor, por mandato de su Magestad, en Çamora, Guillermo de Millis, Medina del Campo, 1553.

${ }^{31}$ F. OCAMPO, ibidem, fol. CCCXXXIII (libro V, capítulo XLV). 
referencias por doquier. Solamente por poner un ejemplo y no aburrir al lector diré que, en el caso de Galicia, este territorio no solamente se convirtió en destino del apóstol Santiago, sino también de Noé. Localidades como Nois (Lugo), Noicela y Noya (Coruña) cuentan en sus tradiciones que Noé y su familia pusieron el pie en esta tierra tras el diluvio universal. De ahí, por ejemplo, que el escudo de Noya esté compuesto por un arca y una paloma. También se dice que el arca de Noé encalló en el monte Barbanza y que casó a su hija Noela con un caudillo local, fundando ambos la ciudad que lleva su nombre. Además, en esta tierra a los monumentos megalíticos se les llama arcas.

De todas maneras, Ocampo es más dado a verbosas especulaciones en torno a ciertos caracteres de la Antigüedad que Garibay, tanto al señalar la excelencia y longevidad de los hombres, como al acreditar la existencia de seres fabulosos desaparecidos después, como los gigantes, sirenos, faunos, etc. de suerte que siente como verdadero el principio de la «vejez de la Natura» ${ }^{32}$ en su tiempo, un tema que ha llegado al folklore europeo. También incide Ocampo en el campo etimológico ${ }^{33}$, pero donde más influyó en Garibay fue en la indagación y estudio de la Onomástica y la Etnografía. Sin embargo, Ocampo no creía que la lengua general de aquellos remotísimos tiempos hubiera sido «la que los Vizcaynos agora hablan», aspecto éste donde se da la mayor discrepancia con su seguidor $^{34}$, desacuerdo que no se da en lo del «cantabrismo» ${ }^{35}$. Pero, a la postre, el alumno se impuso al maestro, y hay que señalar que los mismos que aprovecharon ampliamente el Compendio de Garibay utilizaron muy poco la Crónica de Ocampo.

De hecho, la Crónica fue perdiendo valor muy pronto, y poco después de que Garibay publicara su Compendio, Ambrosio de Morales -como hemos señalado anteriormente- dio a la imprenta la continuación de la Crónica de Ocampo, pero donde ya se apoya en los textos más fidedignos, y en inscripciones y en lápidas. Asimismo, da una visión de la España romana sensiblemente superior a la de Garibay, porque tenía un conocimiento superior de los textos griegos de la Numismática, de la Arqueología, etc. Realmente fue una lástima que la prosecución de la Crónica no se publicara antes del

\footnotetext{
32 OCAMPO, ibidem, fol. XXII (libro I, capítulo VI).

${ }^{3}$ En este aspecto no dejó Ocampo de hacer algún pinito etimológico a costa del euskera. Así, el nombre del monte «Sollube», que escribe «Solúé» dice que era «Solórue» antes y que significa «Sobrio», asociándolo a los siluros, etc.: "Conforme a lo qual aquellos Vizcaynos antiguos solían llamar Soloroa a qualquier heredad o posesión donde situaban sus grangerias en aquellos montes, agora le dizen Soroa, quitando la sílaba del medio por hablar mas polido y mas galan” (ibidem, fol. CXI (libro IV, capítulo III).

${ }^{34}$ OCAMPO, ibidem, fol. XXXII (libro I, capítulo X).

35 OCAMPO, ibidem, fol. CCXI (libro III, capítulo III).
} 
Compendio, porque le habría dado a Garibay más conciencia de ciertos hechos y afirmaciones.

\section{Tubal y la primogenitura de los vascos}

En todo caso, y volviendo al asunto de los reyes fabulosos, hay que advertir que, aunque en Italia y otras partes hubo eruditos que detectaron pronto las supercherías de Annio, Garibay no parece que se dejó influir por tal crítica, y continúa elaborando su teoría. Y si en el Compendio aún no es tan explícito, el «tubalismo» se convierte ya en «vasco-iberismo» propiamente dicho, enunciándose de un modo formal en las "Grandezas de España"36. Así, en línea directa, los descendientes de Tubal y del segundo rey, es decir «Ibero», quedan en las montañas de Cantabria (en tierra vasca, según dogma de los vascocantabristas); y otros de los iberos no sólo se extienden por la península sino que rebasan sus límites, tomando como prueba un pasaje de Séneca en que se dice que en Córcega había reliquias lingüísticas y otras similares que se hallaban entre los cántabros.

Es evidente que nuestro historiador tenía una idea muy alta de las riquezas naturales de España (“assi venían las naciones estrangeras a ganar riquezas a España, como agora van a las Indias los mismos españoles”37), pero, entonces, ¿porqué, siendo la península tan rica, Tubal se asentó en las montañas no famosas por su riqueza? Y es aquí donde Garibay hace gala del mundo en que nació, del medio natural, óptimo para llevar una vida sencilla y primitiva, convirtiendo su prosa en una alabanza del país que le vio nacer: unos «Laudes Cantabriae» podríamos decir, recordando los «Laudes Hispaniae» ${ }^{38}$.

\footnotetext{
${ }^{36}$ En esta obra, de GARIBAY Y ZAMALLOA, "Grandezas de España: noticias de los títulos y Casas Ilustres de ella y otras particularidades", Memorial histórico español, Real Academia de la Historia, v.VII, Madrid, 1854, recogió algunos de los mejores y más extensos fragmentos de elegías y cantares medievales conservados (cf. CARO BAROJA, Los vascos y la Historia; L. MICHELENA, Sobre el pasado de la lengua vasca, Auñamendi, San Sebastián, 1964), además de compilar dos pequeñas colecciones de refranes para Juan de Idiáquez -publicadas por AIZKIBEL ("Refranes vascongados" en Memorial histórico español, Real Academia de la Historia, v.VII, Madrid, 1854, 629-660 [Separata en Madrid: J. Rodríguez, 1854. Edición facsimilar, Librerías París-Valencia, Valencia, 1995]); URQUIJO (El refranero vasco: I. Los refranes de Garibay) y ZUBIAUR Y ARZAMENDI "El léxico vasco de los refranes de Garibay", Anuario del Seminario de Filologia Vasca "Julio de Urquijo", 10, 1976, 47-144.)-. En esta obra Garibay reescribe el material que se repetía en las Crónicas, aportando muchos datos e ideas nuevas (ZUBIAUR BILBAO, Las ideas lingüísticas vascas en el s. XVI). En definitiva, cuenta la venida de Tubal, y también explicita que sus descendientes se establecieron en Cantabria y en Navarra, de donde se extenderían por toda la Península.

${ }^{37}$ E. de GARIBAY Y ZAMALLOA, Compendio Historial, I, 65 (libro III, capítulo III). El capítulo entra en la tradición de «Laudes Hispaniae»

${ }^{38}$ Estos elogios a su país natal, de Garibay, se copiaron muchas veces, según, J. Caro Baroja, y existen copias manuscritas del siglo XVII, con añadiduras.
} 
Y esta empresa apologética discurre por el capítulo IV del Compendio, describiendo "como Tubal enseñó a los suyos las leyes de la naturaleza, y les dio orden de bien vivir, y que la lengua de Cantabria, llamada ahora Bascongada, fuera la primera d'España, para cuya verificación se refieren razones notables"39.

También es curioso, y en esta observación sigo a Zubiaur Bilbao ${ }^{40}$, que para Garibay la abundancia de términos vascos en la onomástica del País Vasco en general es también un argumento del que se sirve para probar el origen tubálico del euskera: "Venido Tubal y sus gentes [...] a cada casa de las que ivan poblando, ponían su nombre propio, segun esto tan antiguo se conserva hasta nuestros días, y todas ellas en general tienen su origen y denominación de la mesma lengua de la tierra"41.

Con respecto a las «razones notables» con que Garibay finaliza el anteúltimo párrafo, éstas son curiosas desde el punto de vista metodológico, por rudimentaria que sea la exposición de las mismas. Hay, en primer lugar, unos paralelismos toponímicos que pueden producir distintos efectos. Comparar «Gorbea» con «Gordeya»; el nombre del «Araxes» guipuzcoano con el «Araxes» virgiliano de Armenia; o el nombre de «Aralar» con el de «Ararat» no da mucha talla de lingüista; e incluso creer que la ferrería mondragonesa de «Babilonia» podía relacionarse con la famosa ciudad, demuestra gran candidez ${ }^{42}$.

De todas maneras, hay algo que da razón funcional a esta tendencia, y es que si los españoles en Indias han llamado Córdoba, Cuenca o Granada a las ciudades que fundaban, ¿porqué los iberos, mejor dicho sus reyes, no iban a dejar memoria de sus asentamientos viniendo de la lejana Asia a estas latitudes?

Asimismo, en lo que respecta al carácter del vascuence, afirma Garibay, primero, que "De grande consideración y misterio es [...] ver que, a lo menos en España, todos los niños desde su natividad traen esta lengua y misterio, porque las primeras palabras que hablan son tayta, que assí llaman al padre, y mama, que assí llaman a la madre: nombres por

\footnotetext{
${ }^{39}$ E. de GARIBAY Y ZAMALLOA, Compendio Historial, I, 89-93 (libro IV, capítulo IV).

${ }^{40}$ ZUBIAUR BILBAO, Las ideas lingüisticas vascas en el s. XVI, 115.

${ }^{41}$ GARIBAY Y ZAMALLOA, Compendio Historial, t. I, 1. IIII, cap. IIII, 72; en ZUBIAUR BILBAO, Las ideas lingüisticas..., 115.

42 Pero, por paradoja, los puntos más vulnerables de la obra de Garibay son los que acaso más fama le dieron entre propios y extraños. En estos puntos, debatidos aún, sobre Historia Antigua, sí desarrolló algo de su cosecha, y que es más interesante desde el punto de vista filológico que desde otros. Porque identificar el nombre de la población guipuzcoana de Régil (Errezil en euskera) al de «Aracillum» (al que se refieren los historiadores tratando de la guerra de Cantabria) no es más aventurado que creer que «Aracillum» se refiere a la población cántabra de Aradillos, identidad que sí recogen y dan por cierta varias páginas que tratan sobre esta población y sobre la historia de Cantabria.
} 
cierto de la lengua de Cantabria, en la qual al padre llaman Ayta y a la madre $A m a " 43$

En esta cuestión, como certeramente ha señalado Zubiaur Bilbao, ${ }^{44}$ Garibay se manifiesta aquí como el primer escritor vasco en usar el lenguaje infantil como argumento que prueba la condición «natural» de una lengua, siendo éste un tema que llamó poderosamente la atención de los renacentistas, y que sirvió para iniciar tímidamente el alejamiento del mito del hebreo como primera lengua de la Humanidad.

En segundo lugar, Garibay afirma el carácter puro de su lengua: "La qual desde el patriarca Tubal hasta nuestros días se ha conservado en esta tierra, sin que jamás se aya podido introduzir otra ni mezclarse con naciones estrañas fuera de su ley, agora sea por la fortaleza de las tierras, agora por la de las gentes, agora por lo uno y lo otro"45.

Abundando en el mismo tema, Garibay califica a lengua vascongada de «pura y perfecta»y, en su opinión, tiene alguna relación con la lengua de Armenia (el arameo, según creía él), "pero no tiene mezcla con la latina, ni con la griega, y muy menos con la hebrea, y no con la chaldea"46. Por último, respecto a la estructura lingüística y a la enseñanza del euskera, afirma que hacer una gramática no sólo sería factible sino relativamente sencillo: es lengua que con menos preceptos que para la latina se podía hazer gramática de enseñar fácilmente. Sin esto es fácil de deprender (sic) continuándola, como la esperiencia cada día lo enseña ${ }^{47}$.

En definitiva, dejando las especulaciones en torno al patriarca Tubal, en las que siguió impertérrito, en el libro II de las "Grandezas", el título VI -donde trata sobre la antigüedad de la lengua cántabra, es decir, del euskera- Garibay amplió lo que había escrito en el primer tomo del Compendio. El empleo que hace de la palabra «íbero» ya se identifica totalmente como un «vasco iberista» a ultranza, y los “iberos que son los españoles, de los quales iberos fueron después llamados los celtíberos"48, hablaron vasco, ni más ni menos.

Con todo, y teniendo en cuenta los distintos intereses del momento, y que las

\footnotetext{
${ }^{43}$ GARIBAY Y ZAMALLOA, Compendio Historial, t. I, 1. IIII, cap. IIII, 77; en ZUBIAUR BILBAO, Las ideas lingüisticas..., 125.

44 ZUBIAUR BILBAO, Las ideas lingüisticas vascas en el s. XVI, 30-31.

45 GARIBAY Y ZAMALLOA, Compendio Historial, t. I, 1. IIII, cap. IIII, 77; en ZUBIAUR BILBAO, Las ideas lingüisticas..., 126.

46 ZUBIAUR BILBAO, ibidem, 78.

47 GARIBAY Y ZAMALLOA, Compendio Historial, t. I, 1. IIII, cap. IIII, 78; en ZUBIAUR BILBAO, Las ideas lingüisticas..., 132.

${ }^{48}$ E. de GARIBAY Y ZAMALLOA, “Grandezas”, 1, fols. 49 r.-51 vto (libro II, túlo VI).
} 
teorías sirven también para ocultar otros alicientes e incluso ganancias, quiero reiterar el universo identitario y en la posición de Garibay, quien reiteradamente insiste en la "primogenitura" de los vascos respecto a los otros pueblos de España, es decir, que son los españoles más originarios. Y en este sentido quiero reseñar la propia la condición de vasco de la que Garibay hace gala, que para él no deja de ser como la forma más genuina y significativa de la autoctonía española.

\section{E1 vasco-cantabrismo y la crítica. Defensa de Garibay}

Han pasado cuatrocientos años desde que lo escrito por Garibay en las "Grandezas" quedó sepultado. En ese tiempo hubo muchos, no sin acritud, que discutieron su tesis, combatieron el vasco-cantabrismo y juzgaron, en conjunto, que eran dos argumentos engañosos para defender ciertas exenciones y privilegios de los vascos. Lo paradójico es que es que mientras que Florián de Ocampo en el siglo XVI y el maestro Flórez en el siglo XVIII discrepaban del vasco-iberismo, por ciertos recelos, llegó el siglo XX... y el vasco-iberismo fue tesis querida de ciertos autores, con tendencia unitaria, y entonces fue combatida por los vascos, que mantenían puntos de vista contrarios por razones hostiles al unitarismo.

Decía Garibay en 1556: "Desde que comencé á tener alguna inteligencia y cognocimiento en las historias y antigüedades del mundo, y muy en particular en las de España vine a considerar, como esta habia carecido de una historia general y universal, desde su primera población, después del universal diluvio hasta nuestros tiempos, con haber tenido en todos sus siglos varones doctos en todas sus facultades, y por ser fragmentos todo lo escrito é intentado por algunos. Con esta consideración, comencé a escribir algunas cosas destos reinos y de fuera dellos en el dicho año de 1556 (...)" ${ }^{49}$.

El reproche del historiador está ahí, con la conciencia de la necesidad de ordenar la historia en previsión de los inconvenientes que se pueden seguir de no hacerlo a tiempo y también de la culpa mayor en quien descuida lo propio habiendo trabajado tanto en lo ajeno. Esta «afición» por las «escrituras y relaciones» que hagan «ver y entender», con «mayor luz la verdad antigua», entrañaba sin duda el riesgo de tomar por verdaderas las noticias de ciertos cronicones.

En efecto, encargado de velar por los intereses de Guipúzcoa en la corte

${ }^{49}$ E. de GARIBAY Y ZAMALLOA, Compendio Historial, f. 85 v. 
(bibliotecario real desde 1566 y cronista real desde 1592), cuando llegó el momento en que la provincia quiso presentar, para su publicación, un cuerpo de leyes, ordenadas por títulos y capítulos, Garibay se dio cuenta que la compilación era imperfecta y, que, por lo tanto, podía ser perjudicial. Estaba incompleta, falta de desarrollos teóricos, aclaratorios; y la parte histórica, en que se debía justificar las libertades y privilegios que de continuo se tenía que alegar o defender, era nula. Propuso, o por lo menos ideó, un plan perfecto de edición, que por el momento no se llevó a cabo. Garibay tenía vocación de secretario, pero alma de archivero.

Cuenta J. Caro Baroja que el poeta latino Rutilio, pagano ardiente en el ocaso del Paganismo, entusiasta de Roma cuando el Impero no era más que una sombra, expresó odio terrible por los judíos. Consideraba que en aquel pueblo estaba «radix stultitiae»; el origen de todos los males que azotaban a Roma. Así, para este pagano y patriota fervoroso, la «radix stultitiae» la contenían los (supuestos) los generadores del Cristianismo; mientras la «radix sapientiae» correspondía a otros, evidentemente. En todo caso, la raíz de los hechos de los hombres es una coas y el resultado, bueno o malo, otra. De la misma manera, la raíz de una investigación histórica puede ser, también, considerada algo distinto a la misma investigación, en «nuestro» momento. Puede incluso que una raíz mala de algo bueno y que una raíz buena dé algo malo. Y también es posible que la raíz, con independencia de su maldad o bondad, produzca cosas, buenas y cosas malas. Así, una lista fabulosa de reyes de España, forjada por un falsario que quería adular, sin duda, a los españoles triunfantes en Italia a fines del siglo XV, dio como curioso resultado el que, por primera vez, se planteara la hipótesis del «vasco-iberismo» con datos plausibles. De Garibay a Hugo Schuchardt hay distancia en todo: en siglos y conocimientos. Pero la «radix» es una. De Garibay a Menéndez Pidal acaso no haya tanta distancia en los más profundo de su alma; porque los dos eran españoles ${ }^{50}$.

Y continuo citando a Caro Baroja, que apunta cuestiones sumamente importantes al final del libro que estoy utilizando como guía: "El «vasco-cantabrismo» puede ser falso históricamente. Lo es en parte. Pero ha sido una «idea-fuerza» (...) Garibay no podía haber hablado de la «Europa de las coronas», porque las patrias de él y sus contemporáneos eran herederas de aquella Europa de reyes coronados en la que Garibay estaba integrado, de suerte que no se le ocurrió jamás que el reino de Castilla y el de

${ }^{50}$ J. CARO BAROJA, Los vascos y la Historia..., 354. 
Aragón, o los de Navarra o Granada, estuvieran unidos sólo por abajo, por la base geográfica peninsular, sino por arriba: precisamente por las coronas, colocadas sobre una misma cabeza" 51 .

Y remata así la faena, válgaseme el símil: "Que en el siglo XVI se pudiera ser imperialista y monárquico de un lado y partidario de las libertades forales de otro, es algo que hay que admitir, nos guste o no. Lo que no cabe es enjuiciar a los hombres de ayer con razonamientos, juicios y prejuicios, incubados del siglo XVIII a acá: sean «vasquistas» o «castellanistas», porque aquel «providencialismo castellano» que se ha dado hasta nuestros días como una verdad científica es tan calamitoso como cualquier otro providencialismo histórico. Si en el futuro se ha de defender la unidad de España no será, ciertamente, a base de dogmas ni de razonamientos que gustan a los unitaristas de hoy, o de los que gustaban a los hombres del XIX"52.

Y termina el libro mostrándonos al Garibay más cercano, al español de su época, con sus viajes y creencias, y de quien, afirma, se acordó el mismo Lope de Vega:

"Garibay no es de los que matizan demasiado como historiador, aunque marque diferencias entre épocas y épocas. Sus juicios son los propios de un español de su época. Ha visitado los Países Bajos, ha visto Amberes y París, ha recorrido Francia: Toledo o Madrid le interesan más, pese a que no fue ni toledano ni madrileño. Ve el mundo desde donde lo veía también su rey, que tenía experiencias juveniles más abundantes aún. No cabe duda de que hay un factor de ensimismamiento religioso y monárquico que les dominó, como a otros españoles. Que esto fuera bueno o malo es lo de menos. Lo necesario es estudiar a los hombres en sus «dimensiones», sin presuponer que existe en ellos esta o aquella limitación o flaqueza, esta o aquella grandeza o bondad. A veces ni los contemporáneos mismos «ven en lo que es». Pese, pues a estos rasgos que destaco resultó, en fin, que «Garibay» vino a ser sinónimo de «vizcaíno»o vasco. Nada más. Lope de Vega, en la escena segunda del acto cuarto de La Dorotea, al hacer burla del culteranismo, da un soneto burlesco, que termina así:

«Tú, lector Garibay, si eres bandurrio,

Aplaúdelos, que son cultidiablescos...»

Más adelante, al aclarar el sentido del soneto, dirá: «Garibay se toma aquí por vizcaíno, como Roma pro Romanis y Ceres por el trigo». ¿Pero qué castellano ha hablado de Vizcaya o de tierra vasca en general con el amor y respeto con que habló Garibay de Castilla y de 
otras partes de España?"53

\section{Los vascos en el espejo de España. A modo de conclusión, y mirando a la actualidad}

Esta última reflexión lúcida de J. Caro Baroja sobre el vasco Garibay, su obra y su época, es muy apropiada para esbozar unas líneas generales finales sobre lo que han sido los vascos a lo largo de la historia, así como la relación que han tenido con España.

Es cierto que una identidad colectiva como pueblo suele ser un fenómeno social profundo, duradero y compartido, por lo que suele requerir un largo período de constitución, y, en este sentido, creo que ha sido la tradición foral la única capaz de haber construido esa identidad política de los vascos. Ninguna otra tradición o experiencia histórica ha jugado un papel comparable a la experiencia de la foralidad en la configuración de una identidad histórico-política vasca.

Pero cuando hablo aquí de foralidad no me estoy refiriendo al conjunto de instituciones reguladoras de la vida de los vascos en el Antiguo Régimen, sino esencialmente a su forma específica de inserción en España, y es en este sentido que el foralismo puede ser considerado como el elemento históricamente conformador de la identidad o personalidad política de los territorios vascos de España.

El rasgo que más me interesa destacar de la tradición foral es su experiencia de profundo autogobierno. Pero el autogobierno del sistema foral no estaba fundado, como pretende una historiografía nacionalista, en ideologías soberanistas, sino en la ideología y práctica del pactismo utilizada por las castas gobernantes del País (aunque muchas veces mediante la discriminación lingüística y económica del pueblo llano). Así, frente a la cultura de la confrontación como principio moldeador de la identidad de los pueblos, la cultura de la tradición foral se fundaba en el pactismo, basado a su vez en la lealtad y confianza mutuas entre (el gobierno) del territorio foral y el del conjunto de España ("la Corona"), el cual era aceptado por el común de la población como la forma "normal" de ejercer su identidad.

En este sentido, la tradición foral configuró a los territorios históricos vascos como una forma políticamente diferenciada de ser españoles. Esta identidad se fue configurando y consolidando por la propia persistencia del régimen foral vasco, el único

${ }^{53}$ J. CARO BAROJA, ibidem, 362-363. 
de España que se prolongó hasta la modernidad (un siglo y medio más allá de los fueros de los territorios de Aragón).

Esta forma de inserción tradicional de los vascos en España entró en crisis y finalmente desapareció casi por entero (salvo el importante residuo del Concierto y de la Ley Paccionada con Navarra) a lo largo del siglo pasado. A la postre, esto (junto con otros factores ligados a una rápida entrada en la modernidad) generó una grave crisis de identidad política en grandes sectores del País. Y esta crisis de identidad constituyó a su vez un importante caldo de cultivo para el surgimiento y expansión del nacionalismo vasco

Por ello, es importante comprender las diferencias más significativas entre las respectivas formas de identidad política de lo vasco que configuran el foralismo y el nacionalismo. La tradición foral es resultado de un proceso histórico que consolida unas relaciones donde la identidad política vasca es compatible con la española a través de esa cultura del pactismo y de la lealtad mutuas. El nacionalismo, en cambio, se formula como una ideología de respuesta a una determinada situación histórica de crisis de identidad. En el nacionalismo, la identidad política se construye en realidad sobre la confrontación (como si los vascos, para serlo, necesitaran de un enemigo) y donde ambas identidades políticas y ambas comunidades (Euskadi-España) son excluyentes, porque la identidad vasca se configura frente/contra España.

Esta humilde reflexión no pretende glosar los presupuestos tradicionales de la foralidad, sino reivindicar el "talante" y la virtualidad de la filosofía del sistema. En este sentido, sería erróneo pretender descalificar todo aquello que "huela" a foralidad, considerando a ésta sólo como un residuo del Antiguo Régimen. Comprender como vivían la foralidad los vasconavarros de los siglos anteriores (el de Garibay es un claro ejemplo de esa vivencia, como el de tantos otros vascos a lo largo de estos siglos) es útil en la medida en que puede ayudar a idear nuevas fórmulas de articular la identidad política de los vascos que partan de lo que hemos realmente sido.

Porque esa era -salvando las distancias y siempre ateniéndonos al tiempo que nos ha tocado vivir-la condición de vasco de la que Garibay hace gala, su forma más genuina y significativa de la autoctonía española, la manera propia de ser miembro de las Españas; siempre conservando sus raíces vascas, a la vez que-como diríamos en la actualidadcompartiendo y construyendo un proyecto común con el resto de pueblos y ciudadanos 
que componen España. 